\title{
THE ROLE OF OCCUPATIONAL HEALTH SERVICES IN CANCER PREVENTION - WHICH FACTORS DETERMINE THE IMPLEMENTATION OF PREVENTIVE MEASURES?
}

\author{
MARTA WISZNIEWSKA ${ }^{1}$, ANDRZEJ MARCINKIEWICZ ${ }^{1}$, AGNIESZKA LIPIŃSKA-OJRZANOWSKA ${ }^{1}$, \\ KATARZYNA KALSKA-SOCHACKA ${ }^{2}$, and JOLANTA WALUSIAK-SKORUPA ${ }^{1}$
}

${ }^{1}$ Nofer Institute of Occupational Medicine, Łódź, Poland

Department of Occupational Diseases and Environmental Health

${ }^{2}$ University of Łódź, Łódź, Poland

Science Centre

\begin{abstract}
Objectives: Epidemiological data on cancer diseases are alarming. The workplace has become an increasingly important site for disseminating health information and implementing health promotion activities. Occupational medicine physicians (OMPs) have the opportunity to carry out primary and secondary preventive activities focused on civilization diseases, especially cancer. The aim of this study was to evaluate the potential of OMPs in cancer prevention, including the analysis of factors determining the implementation of preventive measures, as part of standard healthcare for employees. Material and Methods: The study was conducted among 362 OMPs. The interviews were carried out by the computer assisted telephone interview (CATI) method. Results: Over $60 \%$ of the surveyed OMPs are ready to implement cancer preventive activities among employees. The doctors with the longest seniority in occupational health services are more likely to declare unwillingness to implement cancer preventive activities. Patient's consent, informing women about the program and adjusting the time of the medical visit are the most important conditions for introducing cancer prevention programs by OMPs. Neither seniority nor the number of examinations performed by a physician influenced the currently implemented cancer preventive activities as part of occupational health services (including the evaluation of cancer risk factors occurrence among employees). Conclusions: In Poland, OMPs are willing to implement cancer preventive activities among employees, but their current activity in this area is limited and needs development. The most specific actions should be addressed to doctors with the longest seniority in occupational health services, who are frequently unwilling to implement cancer preventive activities. Strengthening the preventive potential of Polish occupational health services requires a systemic approach to the scope and way of action of healthcare professionals. Int J Occup Med Environ Health. 2021;34(6):723-36
\end{abstract}

Key words:

mammography, occupational health services, cancer prevention, cytology, surveillance, screening program

Funding: this study was supported by the National Centre for Research and Development (project No. IS-2/94/NCBR/2015 entitled "Healthy Woman's Diary in the prevention of cancer," project manager: Prof. Marta Wiszniewska).

Received: November 19, 2020. Accepted: February 18, 2021.

Corresponding author: Marta Wiszniewska, Nofer Institute of Occupational Medicine, Department of Occupational Diseases and Environmental Health, św. Teresy 8 , 91-348 Łódź, Poland (e-mail: Marta.Wiszniewska@imp.lodz.pl). 


\section{INTRODUCTION}

Epidemiological data on cancer diseases are alarming. In 2017, the Polish National Cancer Registry received information on almost 165000 new incidence cases and 99600 deaths due to cancer [1]. In the Polish society, almost 1.08 million people have been diagnosed with cancer within the preceding 15 years, of which 815000 cases were diagnosed in the previous 10 years and 515000 cases in the past 5 years [1]. Cancer is the second leading cause of death in Poland. It caused $26.3 \%$ of deaths among men and $23.1 \%$ of deaths among women in 2017. A significant problem is especially visible in the female population because it accounts for $33 \%$ of deaths among young women and $49 \%$ of deaths among middle-aged women [1]. In Poland, the most common cancer among women is breast cancer, which accounts for $22.5 \%$ of all cases, while malignant tumors of the uterus, ovary and cervix constitute $7.3 \%, 4.6 \%$ and $3.0 \%$ of cases, respectively [1].

It is emphasized that the results of cancer treatment in Poland are still worse than in most of the EU member states [1]. The Governmental Population Council of Poland, which acts as the body advising the Prime Minister on matters related to demographic and population policy issues, in the diagnosis of Poland's oncology situation, summarized that a low percentage of early recognized cancers, especially cervical and breast cancers, is caused by the insufficient preparation of doctors and dissemination methods of early diagnosis. The insufficient development of oncological education in the Polish community of healthcare professionals as well as negligence in the promotion of healthy lifestyles are underlined as reasons for delayed cancer diagnosis [2]. It is proven that the introduction of a population-based screening program improved the curability rate for cervical cancer patients in the Dolnośląskie Voivodship [3].

It is stressed that the workplace has become an increasingly important site for disseminating health information and implementing health promotion activities, includ- ing cancer screening [4]. In Poland, in accordance with the provisions of the Labor Code, employees are subjected to obligatory medical examinations resulting in a statement on the fitness for work [5]. Therefore, they have regular contact with a physician providing health checkups. One of the obligatory tasks of occupational medicine services is health promotion and, in particular, implementation of preventive health-oriented programs based on workforce health assessment. Furthermore, the role of occupational medicine services is also to initiate employers' activities aimed at protecting the health of employees, and to provide assistance in their implementation, with special attention on health promotion programs [6].

Taking into account the above data, occupational medicine physicians (OMPs) have the opportunity to carry out primary and secondary preventive activities, focused on civilization diseases, especially cancers.

The aim of this study was to evaluate the potential of OMPs in cancer prevention, including the analysis of factors determining the implementation of preventive measures as part of standard healthcare for employees.

\section{MATERIAL AND METHODS}

\section{Study group}

The study was conducted among randomly selected 362 Polish physicians from occupational health services, with women constituting $68.5 \%$ of the respondents. In addition, 264 respondents indicated that they had a specialization other than occupational medicine. The largest proportion of doctors were specialists in internal medicine $(\mathrm{N}=143,39.5 \%)$ and family medicine $(\mathrm{N}=37$, $10.2 \%$ ). The characteristics of the study group is shown in Table 1.

\section{Questionnaire}

The interview questionnaire consisted of closed, semiopen and open questions. The interviews were carried out by the computer assisted telephone interview (CATI) 
Table 1. Characteristics of the study sample of randomly selected Polish physicians from occupational health services - based on the interviews carried out by the computer assisted telephone interview (CATI) method in November and December 2015

\begin{tabular}{|c|c|c|c|c|c|}
\hline \multirow[t]{2}{*}{ Variable } & \multicolumn{5}{|c|}{$\begin{array}{c}\text { Participants } \\
\left(\mathrm{N}=362^{*}\right) \\
{[\mathrm{n}(\%)]}\end{array}$} \\
\hline & total & $\begin{array}{c}31-40 \text { years } \\
(\mathrm{N}=21)\end{array}$ & $\begin{array}{c}41-50 \text { years } \\
(\mathrm{N}=95)\end{array}$ & $\begin{array}{c}51-60 \text { years } \\
(\mathrm{N}=112)\end{array}$ & $\begin{array}{l}\geq 61 \text { years } \\
(\mathrm{N}=130)\end{array}$ \\
\hline \multicolumn{6}{|l|}{ Sex } \\
\hline women & $248(68.5)$ & $18(85.7)$ & $72(75.8)$ & $72(64.3)$ & $85(65.4)$ \\
\hline men & $114(31.5)$ & $3(14.3)$ & $23(24.2)$ & $40(35.7)$ & $45(34.6)$ \\
\hline \multicolumn{6}{|l|}{ Specialization } \\
\hline occupational medicine & $255(70.4)$ & $11(52.4)$ & $79(83.2)$ & $67(59.8)$ & $94(72.3)$ \\
\hline internal medicine & $143(39.5)$ & $3(14.3)$ & $37(38.9)$ & $49(43.8)$ & $53(40.8)$ \\
\hline family medicine & $37(10.2)$ & $2(9.5)$ & $12(12.6)$ & $12(10.7)$ & $10(7.7)$ \\
\hline \multicolumn{6}{|l|}{ Place of employment } \\
\hline occupational health services unit & $281(77.6)$ & $10(47.5)$ & $80(84.2)$ & $94(83.9)$ & $94(72.3)$ \\
\hline Regional Occupational Medicine Center & $54(14.9)$ & $12(57.1)$ & $19(20.0)$ & $10(8.9)$ & $13(10.0)$ \\
\hline other & $65(18.0)$ & $4(19.0)$ & $7(7.4)$ & $16(14.3)$ & $37(28.5)$ \\
\hline \multicolumn{6}{|l|}{ Seniority in occupational health services } \\
\hline$\leq 15$ years & $97(26.8)$ & $21(100)$ & $46(48.4)$ & $18(16.1)$ & $11(8.5)$ \\
\hline $16-30$ years & $154(42.5)$ & 0 & $47(49.5)$ & $71(63.4)$ & $34(26.2)$ \\
\hline$>30$ years & $108(29.8)$ & 0 & 0 & $22(19.6)$ & $85(65.4)$ \\
\hline I don’t know & $3(0.8)$ & 0 & $2(2.1)$ & $1(0.9)$ & 0 \\
\hline \multicolumn{6}{|l|}{ Examinations performed weekly (M) } \\
\hline$\leq 20$ examinations & $101(27.9)$ & $3(14.3)$ & $20(21.1)$ & $34(30.4)$ & $43(33.1)$ \\
\hline 21-50 examinations & $97(26.8)$ & $4(19.0)$ & $28(29.5)$ & $25(22.3)$ & $39(30.0)$ \\
\hline$>50$ examinations & $110(30.4)$ & $10(47.6)$ & $33(34.7)$ & $37(33.0)$ & $30(23.1)$ \\
\hline it is hard to say/I don’t know & $54(14.9)$ & $4(19.0)$ & $14(14.7)$ & $16(14.3)$ & $18(13.8)$ \\
\hline \multicolumn{6}{|l|}{ Employee's examination time (M) } \\
\hline$\leq 10 \min$ & $67(18.5)$ & $5(23.8)$ & $17(17.9)$ & $24(21.4)$ & $21(16.2)$ \\
\hline $11-20 \mathrm{~min}$ & $228(63)$ & $12(57.1)$ & $68(71.6)$ & $65(58.0)$ & $80(61.5)$ \\
\hline$\geq 21 \mathrm{~min}$ & $34(9.4)$ & $1(4.8)$ & $4(4.2)$ & $12(10.7)$ & $17(13.1)$ \\
\hline no data & $33(9.1)$ & $3(14.3)$ & $6(6.3)$ & $11(9.8)$ & $12(9.2)$ \\
\hline
\end{tabular}

* Age group 25-30 years was not included below because of the sample size $(\mathrm{N}=4)$.

method in November and December 2015. The interviewer read the questions and recorded the answers, using a special computer script.

The questionnaire provided information on whether OMPs ask questions about preventive screening for women (such as cytology, mammography, breast ultrasound) and on the cancer risk factors in a particular patient. The interviewer also asked if during a medical examination the doctors checked whether employees had a family history of cancer, smoked tobacco, abused alcohol, had a diet rich 
in saturated fats, or suffered from overweight or obesity. Moreover, the surveyed physicians were asked if they inquired patients about early menarche or late menopause, and about having children or first pregnancy after the age of 30 years. They were also requested to evaluate the initiative of carrying out additional cancer preventive activities as part of medical surveillance of workers.

\section{Statistical methods}

The statistical analysis of the obtained results was carried out using SPSS v. 2.1. For the categorical variables, the $\chi^{2}$ test of independence with Yates's correction was applied. The data was presented in numbers and percentages of the group in the relation to people representing a given feature. The statistical significance level was set at $p<0.05$.

In order to show correlation between job seniority in occupational health services and age of the surveyed doctors - in the context of the declared readiness to implement described cancer preventive activities - the study sample was divided into 2 groups. The first group included physicians who stated that they were not ready to implement any additional cancer preventive activities (regardless of the indicated reason, i.e., individuals indicating the following answers: "I am not ready to implement the described activities, because I think that it would be too much burden" and "I am not ready to implement the described activities, because I believe that promotion of cancer prevention should not belong to the tasks of an occupational medicine physician"). The second group comprised people who expressed their willingness to implement cancer preventive actions (by providing answers such as: "Yes, I will gladly implement the described activities immediately" and "Yes, I am ready to implement the described activities under certain conditions"). Then, cross-tables and $\chi^{2}$ tests were performed for the following variables: willingness/ reluctance to implement cancer prevention, seniority in occupational health services for employees (distinguished groups: $\leq 15$ years, $16-30$ years, $>30$ years) and age of the respondents.

Conducting further analysis, the respondents were also divided into a group of people who "always" or "in the majority of cases" asked about cancer prevention screening and a group of those who did it "occasionally" or "never." Then, cross-tables and $\chi^{2}$ tests of independence were performed for the following variables: the groups of doctors asking or not about employees' preventive screening, seniority in occupational health services and the number of examinations performed weekly.

In order to compare the numbers in the groups declaring particular current preventive actions, the sample was divided into 2 groups - those who declared that they "always" or "in the majority of cases" verified the occurrence of individual risk factors and those who checked it "occasionally" or "never." Then, cross-tables and $\chi^{2}$ tests were carried out to evaluate whether the declared current preventive actions were independent of seniority in occupational health services and of the number of preventive examinations performed weekly.

\section{RESULTS}

Of the 362 respondents, the physicians from occupational health services units accounted for $77.6 \%$. The majority of those physicians worked at the employees' healthcare system for 16-30 years (42\% of the surveyed doctors). The number of preventive examinations of employees conducted by the respondents weekly varied, but the majority of doctors devoted 11-20 min to perform a check-up (Table 1).

As many as $220(61 \%)$ of the surveyed doctors declared their willingness to implement preventive activities reducing the incidence of cancer among women; 78 (22\%) respondents were ready to take actions immediately, and $142(39 \%)$ would take them under certain conditions. As many as 124 (34\%) of the respondents were not ready to implement cancer prevention as a part of preventive 
care for employees, because they considered that it would overburden them or that it should not be the OMP's task. The statistical analysis demonstrated that the physicians with the longest seniority ( $>30$ years) were less often willing to implement cancer prevention than the individuals from the group with shorter ( $\leq 15$ and $16-30$ years) $\left(\chi^{2}(2\right.$, $\mathrm{N}=342)=16.97, \mathrm{p}<0.001$ ) (Figure 1a).

In order to indicate the correlation between readiness to implement cancer prevention in particular age groups, the above-mentioned division of the sample was applied. The first group consisted of doctors reluctant to implement preventive actions regarding cancer (regardless of the indicated reason), and the second included those who reported readiness to implement them (immediately or under certain conditions). The findings reject the null hypothesis presuming that there would be no correlation between age and the willingness to implement cancer prevention $-\chi^{2}(4, \mathrm{~N}=340)=23.29, \mathrm{p}<0.001$. The younger age groups (31-40, 41-50 and 51-60 years) were more willing than the older age groups (61-65 and $>65$ years) to implement cancer prevention (Figure 1b).

The factors conditioning the implementation of cancer preventive actions among those doctors who were ready to implement preventive actions were also analyzed. In all cases, the test of independence results were non-significant. It means that an indication (or not) of a particular condition as necessary for the willingness to implement cancer prevention does not correlate with the number of examinations performed weekly or with seniority in occupational health services ( $p>0.05$ for all listed conditions) (Table 2).

In Table 3, the analysis of cancer preventive activities currently implemented by the surveyed doctors as a part of preventive care for employees is presented. With regard to the question about cytology and breast ultrasound, there was no reason to reject the zero hypothesis assuming the independence of the following variable: seniority in occupational health services and verification

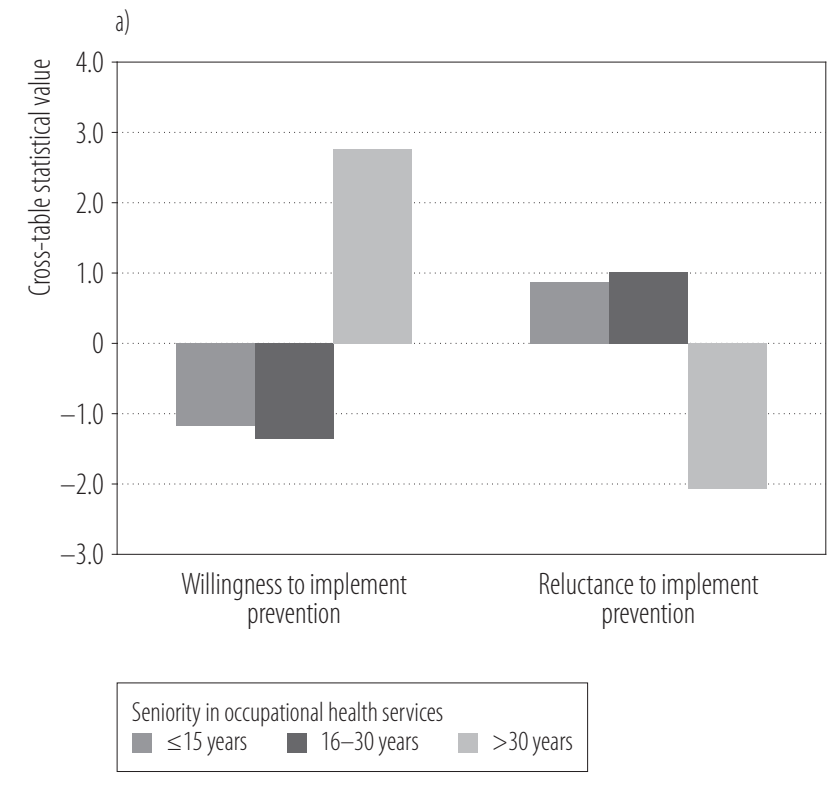

$\chi^{2}(2, \mathrm{~N}=342)=16.97, \mathrm{p}<0.001$.

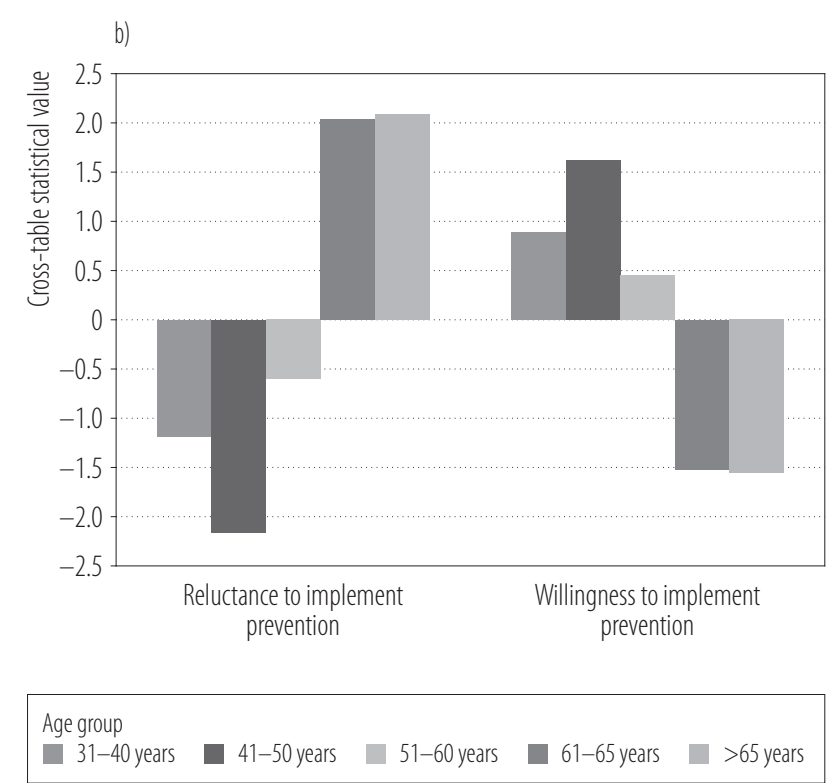

$\chi^{2}(4, \mathrm{~N}=340)=2329, \mathrm{p}<0.001$.

Figure 1. Standardized residuals - deviations between the observed and expected numbers in the groups distinguished due to willingness/reluctance to implement prevention, and a) seniority in occupational health services, b) age groups

("always" or "in the majority of cases" vs. "occasionally" or "never") whether patients attended preventive screenings $(p>0.05)$. The results of the statistical analysis re- 
Table 2. Analysis of factors conditioning the implementation of cancer preventive actions among physicians who are ready to implement preventive actions - based on the interviews carried out by the computer assisted telephone interview (CATI) method in November and December 2015

\begin{tabular}{|c|c|c|c|c|c|c|c|}
\hline \multirow{3}{*}{ Factor } & \multicolumn{7}{|c|}{$\begin{array}{c}\text { Participants } \\
(\mathrm{N}=142 *) \\
{[\%]}\end{array}$} \\
\hline & \multirow{2}{*}{ total } & \multicolumn{3}{|c|}{$\begin{array}{l}\text { seniority in occupational } \\
\text { health services }\end{array}$} & \multicolumn{3}{|c|}{ examinations performed weekly } \\
\hline & & $\begin{array}{l}<15 \text { years } \\
(\mathrm{N}=38)\end{array}$ & $\begin{array}{l}16-30 \text { years } \\
(\mathrm{N}=71)\end{array}$ & $\begin{array}{l}>30 \text { years } \\
(\mathrm{N}=32)\end{array}$ & $\begin{array}{c}<20 \\
(\mathrm{~N}=37)\end{array}$ & $\begin{array}{c}21-50 \\
(\mathrm{~N}=35)\end{array}$ & $\begin{array}{c}>50 \\
(\mathrm{~N}=54)\end{array}$ \\
\hline $\begin{array}{l}\text { Patient's consent for additional activities } \\
\text { related to verification of cancer risk } \\
\text { factors occurrence }\end{array}$ & 78.9 & 84.2 & 77.5 & 75.0 & 81.1 & 77.1 & 81.5 \\
\hline $\begin{array}{l}\text { Informing the patients about increasing } \\
\text { occupational health service for cancer } \\
\text { prevention programs }\end{array}$ & 71.8 & 71.1 & 69.0 & 81.3 & 81.1 & 77.1 & 64.8 \\
\hline $\begin{array}{l}\text { The adequate visit time to perform } \\
\text { preventive activities }\end{array}$ & 70.4 & 68.4 & 71.8 & 68.8 & 73.0 & 74.3 & 68.5 \\
\hline Longer examination & 68.3 & 68.4 & 71.8 & 62.5 & 64.9 & 80.0 & 63.0 \\
\hline The official order from management & 30.3 & 36.8 & 25.4 & 34.4 & 24.3 & 34.3 & 35.2 \\
\hline
\end{tabular}

* For 1 person willing to implement cancer preventive actions, age and seniority were not indicated.

lated to mammography indicate that the null hypothesis about the independence of work experience and questions about mammography considered as part of current cancer prevention should be rejected $-\chi^{2}(2, \mathrm{~N}=298)=6.43$; $\mathrm{p}<0.05$. The individuals from the groups with the shortest and the longest seniority in occupational health services ( $\leq 15$ and $>30$ years) less often declared that they "always" or "in the majority of cases" asked about mammography screening (negative standardized residuals), comparing to the doctors with work experience of 16-30 years (Figure 2).

In the case of the question about attendance of cytology and breast ultrasound among female employees, there was no reason to reject the zero hypothesis assuming the independence of the number of medical visits performed weekly and verification ("always" or "in the majority of cases" vs. "occasionally" or "never") whether patients attended preventive screenings ( $p>0.05$ ). However, the result of the mammography test indicates that the null hypothesis about the independence of the number of examinations performed weekly and the questions about mammography being a part of current cancer prevention should be rejected $-\chi^{2}(2, \mathrm{~N}=255)=6.82, \mathrm{p}<0.05$. The doctors performing $\leq 20$ examinations weekly were more likely to declare that they "always" or "in the majority of cases" asked patients about mammography (positive standardized residuals in the categories "always" or "in the majority of cases") than those conducting more checkups weekly (21-50 and >50) (Figure 3a).

Only the result of the test taking into account seniority in occupational health services and verification of risk factors, i.e., early menarche or late menopause, rejects the zero hypothesis presuming the independence of these variables. The physicians with the longest seniority (>30 years) more often declared that they "always" or "in the majority of cases" asked patients about early menarche or late menopause (positive standardized residuals in the categories "always" or "in the majority 
of cases") than the individuals from the groups with shorter seniority in occupational health services ( $\leq 15$ years and 16-30 years) (Figure 3b).

In the case of the question concerning other risk factors, there was no reason to reject the zero hypothesis on the independence of seniority in occupational health services and verification of particular risk factors ("always" or "in the majority of cases" vs. "occasionally" or "never") ( $p>0.05)$.

In none of the analyses which took into account the number of examinations performed weekly, $\mathrm{p}<0.05$ was demonstrated. It means that there was no reason to reject the hypothesis presuming that the verification of particular risk factors in patients is independent of the number of medical examinations performed weekly (Table 3 ).

\section{DISCUSSION}

In the presented study, $>60 \%$ of the OMPs claimed to be ready to implement cancer preventive activities among employees. Patient's consent, informing women about the program and adjusting the time of the medical visit were the most important conditions for introducing cancer prevention programs by OMPs. The doctors with the longest seniority in occupational health services were more likely to be unwilling to implement cancer preventive activities. Neither seniority nor the number of examinations performed by a physician influenced the currently implemented cancer preventive activities as part of occupational health services (including the evaluation of the cancer risk factors occurrence among employees).

In the Ottawa Charter, the term health promotion has been defined as "the process of enabling people to increase control over, and to improve, their health" [7]. The contemporary definition states that the workforce health promotion is a modern strategy for supporting the economic development of enterprises through coordinated investments in improving their workforce's health [8]. In turn, according to the Luxembourg Declaration of the European Agency for Safety and Health at Work, the workplace health promotion is a collective effort of employers, employees and the society striving to improve the health and well-being of employees [9].

Although occupational medicine services (OMS) tasks include health promotion activities and implementation of preventive health programs, in Poland preventive care for employees is mostly oriented towards obligatory examinations (preliminary, periodical and control). During the check-ups, employees are mainly examined to confirm a lack of contraindications for work at a given position and occupational exposure. Despite the fact that preventive programs and additional health promoting activities could be a part of prophylactic medical care for employees, they are rarely undertaken by OMS [10]. Particular attention is given to the fact that in Poland an OMP is a person to whom the patient - a working person - comes with a referral from their employer, not when a medical problem that necessitates some medical advice or specialist treatment arises. Therefore, OMPs who provide preventive care for employees, due to the fact that they have contact with all types of patients, even those who do not report any symptoms, are an ideal group to conduct broadly understood disease prevention including cancer.

A special emphasis should be put on the increased health awareness of society as in the field of cancer early detection is of crucial importance - in a stadium when the disease may be successfully cured. Breast cancer prevention and control measures should be included in workplace health promotion programs [11]. It was proven by other researchers that important opportunities for health promotion may be achieved by integrating cancer prevention and screening into worksite health promotion programs, and targeted strategies in the workplace should be developed that focus on informing and/or enabling workers to engage in routine cancer screening $[12,13]$.

Health promotion and cancer prevention, implemented through activities aimed at the development of early ma- 


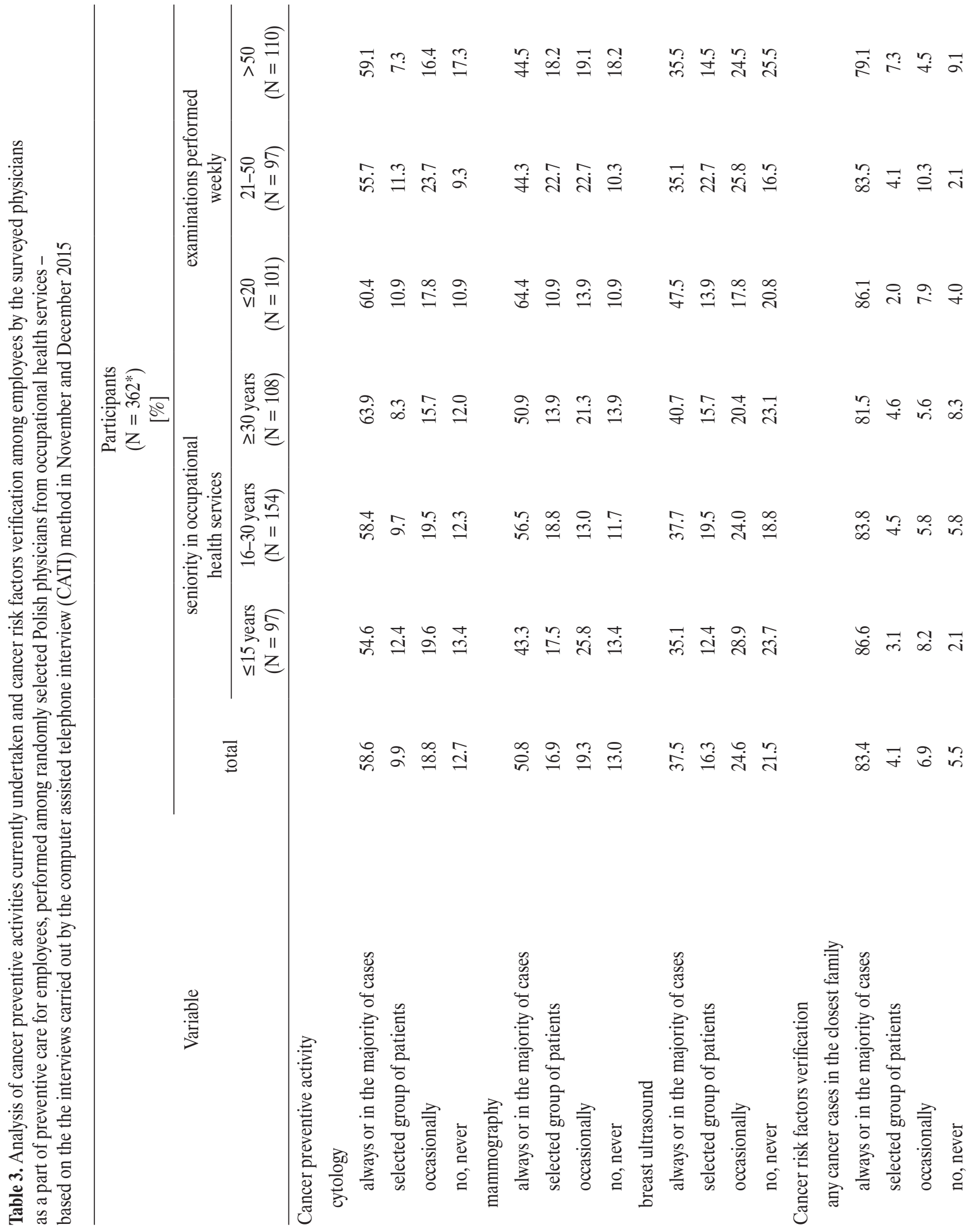




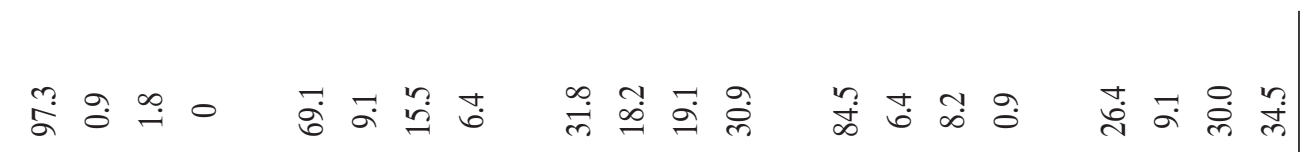

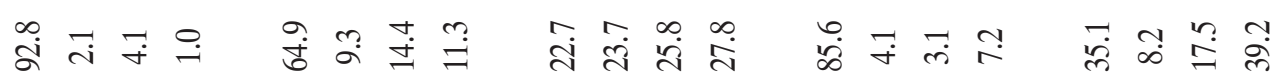
䒘肪

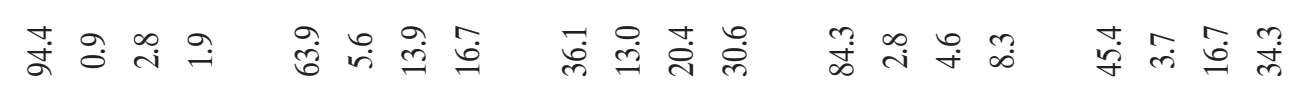

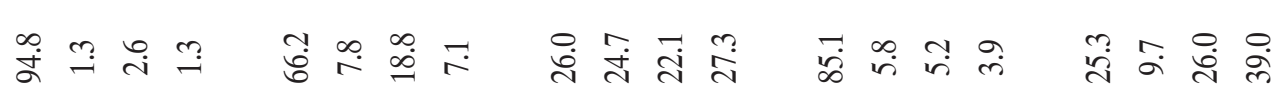

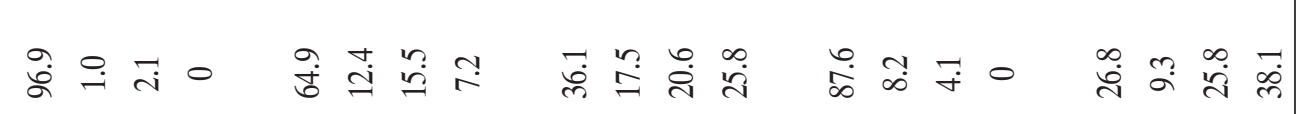

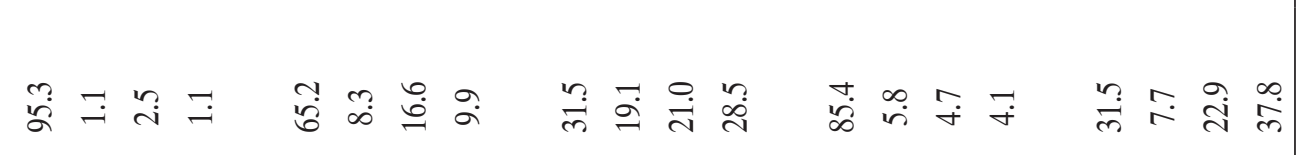

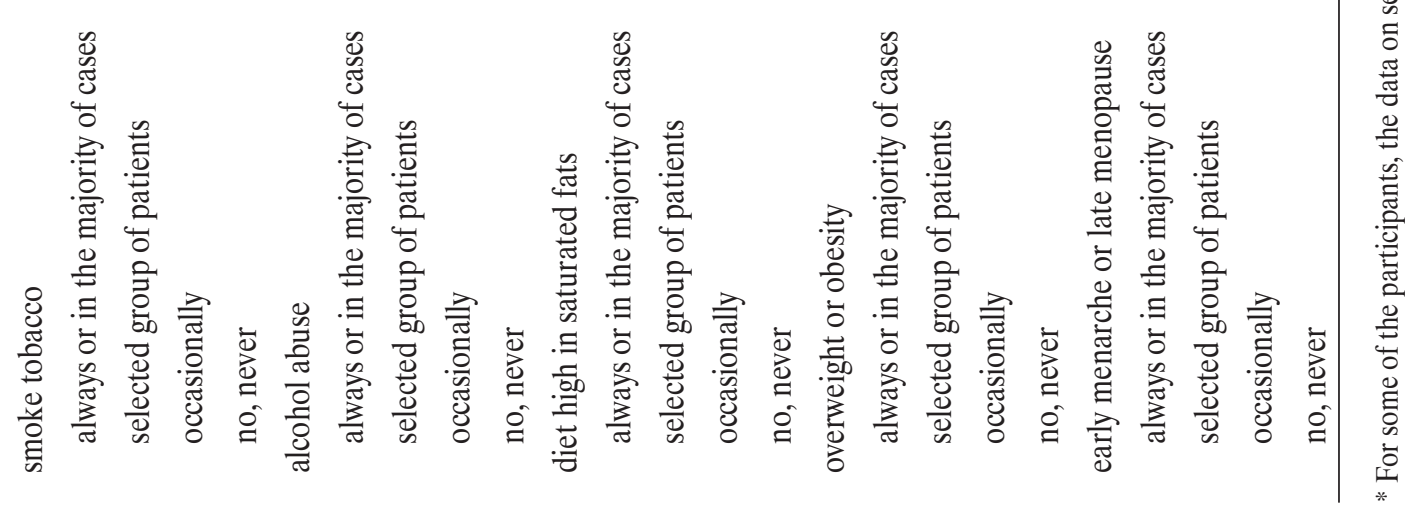




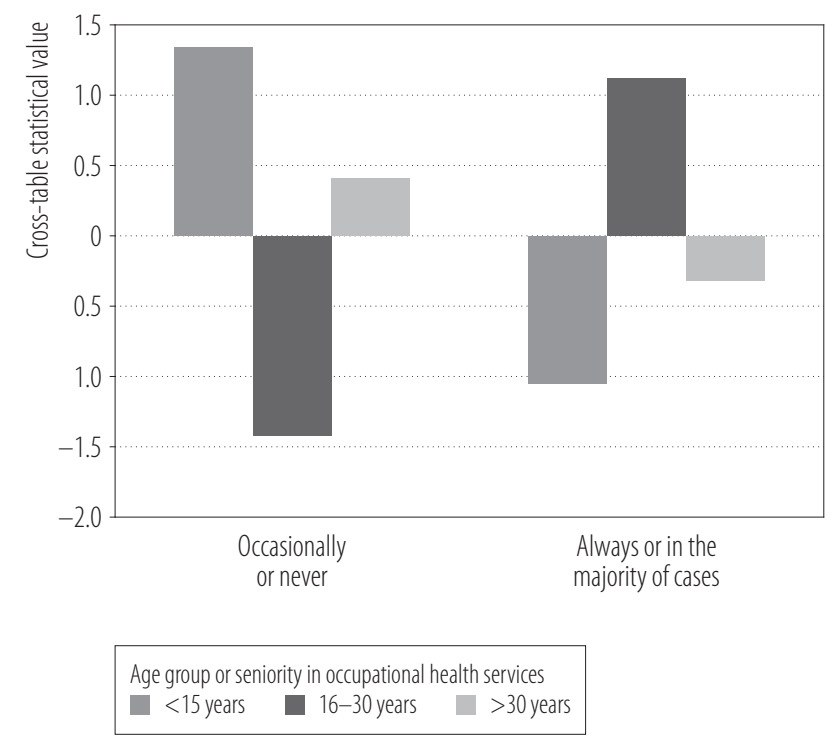

$\chi^{2}(2, \mathrm{~N}=298)=6.43, \mathrm{p}<0.05$.

Figure 2. Standardized residuals - deviations between the observed and expected numbers in the groups distinguished due to currently implemented cancer prevention (the question about mammography screening - "always" or "in the majority of cases" vs. "occasionally" or "never") and seniority in occupational health services

lignancy prevention (consolidation of healthy lifestyle patterns) and primary prevention (disease prevention by controlling risk factors, with particular emphasis on cervical cancer, breast cancer, colorectal cancer and lung cancer) are among the priority actions of the National Oncology Strategy for 2020-2030 implemented in Poland [14]. The National Population-Based Prevention and Early Cervical Cancer Screening Program as well as the National Population-Based Early Breast Cancer Screening Program are available for women from appropriate age groups. However, the most important issue in the implementation of these programs is the participation rate of the target population. For example, in 2010 the participation rate in cytology was only $27 \%$, which confirms an urgent need for further education in order to increase women's health awareness in Poland [15]. The number of women aged 20-69 who declared that they had never had a Pap test carried out was $14 \%$ in 2011, and it was lower compared to 2004 when this percentage equaled 30\% [16,17]. To improve the effectiveness of the National Population-Based Cervical Cancer Screening Program in Poland, the intensive training of doctors and midwives, as well as developing a social educational campaign, are recommended [18]. In Poland, no research concerning preventive pro-health programs in the field of cancer prevention through health promotion adopted by OMS has been carried out so far. The aim of this study was to evaluate cancer preventing actions undertaken by OMPs and to analyze the factors determining the implementation of preventive measures limiting the risk of malignant tumors' developing.

According to registers kept by the Regional Occupational Medicine Centers, in 2015 the number of doctors entitled in Poland to provide preventive healthcare for working people amounted to 7053 [19]. In this study, opinions were collected from a randomly selected representative group of 362 OMPs (providing preventive care for employees) from Poland (including people employed in various types of basic occupational medicine units, e.g., public and nonpublic healthcare institutions, and physicians practicing individually).

The questionnaire study was used to collect data and verify whether during employees' examinations OMPs ask questions about the prevention of cancer diseases and attendance of screenings such as cytology and mammography. An attempt was also made to identify factors that prevent doctors from carrying out preventive actions related to cancer diseases.

It was established by Edwards and Boulet [20] that physicians should not overlook opportunities to recommend mammography screening where appropriate, and include breast examinations as part of regular physical check-ups. Also, the benefits of good occupational health and safety practices have been identified, and the studies concerning workplace cancer prevention initiatives were published in medical literature. For example, Sorensen et al. [21] dem- 
onstrated that the integration of occupational health and safety and health promotion may be an essential means of enhancing the effectiveness of worksite tobacco control initiatives with blue-collar workers.

In the absence of primary cancer prevention programs with the participation of OMPs or other specific regulations in this field, there was a need to create a model of preventive measures for cancer among women, which is integrated with preventive care for employees [22]. One out of 5 doctors $(22 \%)$ declared that they were ready to implement preventive measures immediately. It is worth noting that, within the younger age groups, there were more doctors willing to implement additional activities for the prevention of cancer among employees.

Screening programs at work represent an efficient, costeffective approach for the early detection of cancer [23]. Crombie et al. [24] concluded that education programs at work can have a positive impact on attitudes and practices, including an increased likelihood and confidence in practicing breast self-examination, promoting women to have a physical breast examination, and promoting discussions of breast screening at the workplace. It was also proven by Gadgil et al. [25] that improving breast awareness and access to care in a cohort of women in an occupational healthcare scheme indicates early detection and more conservative treatment of breast cancers.

There is also a large group of OMPs (39\%) ready to implement preventive actions under certain conditions. The most important of these, apart from patient's consent for additional activities related to verification of cancer risk factors occurrence, is the time needed to collect a detailed interview. The vast majority of the surveyed doctors indicated that the time that the planned activities would absorb during the visit should be adequate to doctor's capabilities, and it might even mean that the preventive visit would take more time than currently. On the other hand, a considerable group of physicians providing preventive care for employees verified at least some of the questions

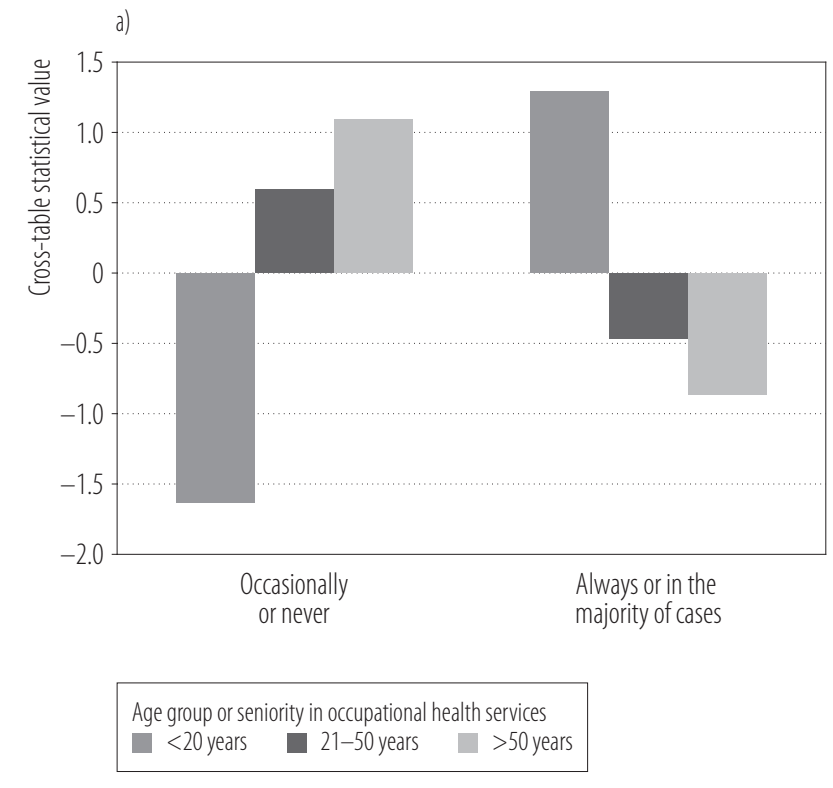

$\chi^{2}(2, \mathrm{~N}=255)=6.82, \mathrm{p}<0.05$.

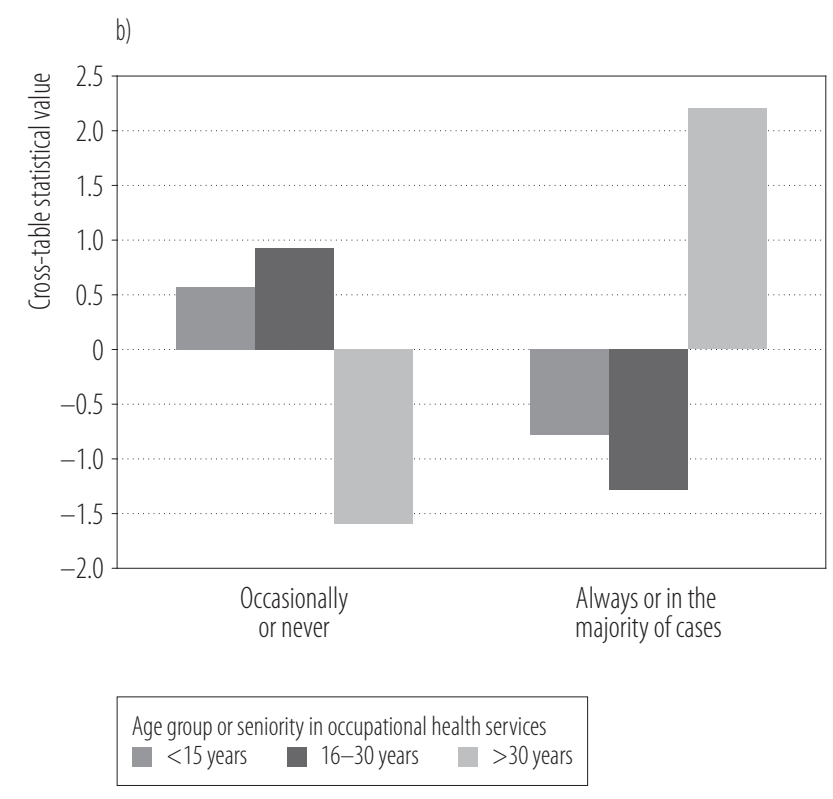

$\chi^{2}(2 . \mathrm{N}=331)=10.84, \mathrm{p}<0.01$.

Figure 3. Standardized residuals - deviations between the observed and expected numbers in the groups distinguished due to currently implemented cancer prevention: a) the question about mammography ("always" or "in the majority of cases" vs. "occasionally" or "never") and the number of preventive examinations performed weekly, and b) the question about early menarche or late menopause ("always" or "in majority of cases" vs. "occasionally" or "never") and seniority in occupational health services 
regarding recently undergone prophylactic examinations (breast ultrasound, mammography, cytology) and the occurrence of risk factors for cancer.

The results of the research indicate that the majority of physicians providing prophylactic care for employees ask their patients about cytology and mammography at least occasionally. However, the doctors who ask such questions to all patients are definitely less common (about one-third of them). As for mammography, the limitation in the group of patients who are asked about the examination may result from age limits for free breast screening under population prevention programs [26].

The risk factors such as cancer occurrence among the patient's closest family members, smoking as well as overweight and obesity are verified always or at least in the majority of cases by $83.4 \%, 95.3 \%$, and $85.4 \%$ of OMPs, respectively. In turn, doctors are significantly less likely to ask about the content of fatty acids in the diet, age at menarche or menopause, having children, and age at first pregnancy. Approximately one-third of them do so always or in the majority of cases.

As many as $27 \%$ of OMPs do not want to conduct cancer prevention because they believe that it would overburden them. Therefore, the length of the questionnaire (the questionnaire focused on recently carried out prophylactic tests of breasts, ovarian and cervical cancer risk factors) [22] seems to be the key issue. By analyzing the results of this research on the time that cancer prevention should take during a medical visit, it can be assumed that $\leq 5$ min would be acceptable for most doctors. Unfortunately, the prolongation of the time predicted for a preventive visit on a large scale is unlikely. It is worth paying attention to the fact that most questions included in the questionnaire are already usually asked by doctors and the usage of the standardized tool would improve the doctor's work.

A certain group of doctors - less than every tenth respondent - is not at all interested in implementing the mea- sures provided for in the project because, in their opinion, cancer prevention should not belong to the tasks of OMPs. This kind of statements were mostly observed in the group of older doctors and doctors with longer seniority. Almost half of the physicians with the longest work experience considered that an additional program would overburden them $(37 \%)$ or admitted that promoting cancer prevention should not belong to the occupational doctor's tasks (11\%). This statement is unacceptable, as the Act on Occupational Health Services, among other documents, requires occupational doctors to undertake preventive activities [6]. Furthermore, the need to change the approach to workers' health, from the so-called occupational perspective in which the priorities include aspects directly related to work (such as occupational diseases or accidents at work) to the approach typical of public health, in which attention is paid to all elements of working person's health (including prevention of civilization diseases), has been postulated for a long time.

It is emphasized that a specialist in occupational medicine should act not only as a physician, but also as an expert in the work-health relationship, in all its aspects: prevention, diagnosis and treatment. Both as part of an interdisciplinary team and working independently, OMPs should participate in supporting the health of people working in healthy and safe conditions. The EU guidelines on the competences of physicians who take care of employees emphasize the role of physicians primarily as advisers (at the individual and entire facility level; among others, detecting and indicating organizational irregularities, having a real impact on the health and comfort of employees, as well as suggesting changes, methods and measures of their introduction) and as coordinators of information systems (through collecting and disseminating information related to health and safety in the work process, as well as designing and implementing training and health promoting programs). This approach was also presented in the report prepared by WHO in 2012, entitled: "Situation analy- 
sis and recommendations for stewardship on workplace health promotion in Poland" [27].

\section{CONCLUSIONS}

In Poland, OMPs are willing to implement cancer preventive activities among employees, but their current activity in this area is limited and needs development.

The most specific actions should be addressed to doctors with the longest seniority in occupational health services, who are frequently unwilling to implement cancer preventive activities.

Strengthening the preventive potential of Polish occupational health services requires a systemic approach to the scope and way of action of healthcare professionals.

\section{REFERENCES}

1. Didkowska J, Wojciechowska U, Czaderny K, Olasek P, Ciuba A. Cancer in Poland in 2017. Warsaw: Ministry of Health; 2019.

2. Potrykowska A, Strzelecki Z, Szymborski J, Witkowski J. Cancer incidence and mortality versus the demographic situation of Poland. Warsaw: Rządowa Rada Ludnościowa; 2014.

3. Zielecka-Dębska D, Błaszczyk J, Błaszczyk D, Szelachowska J, Lichoń K, Maciejczyk A, et al. The effect of the populationbased cervical cancer screening program on 5-year survival in cervical cancer patients in Lower Silesia. Adv Clin Exp Med. 2019;28(10):1377-83, https://doi.org/10.17219/acem/109759.

4. Coughlin SS, Caplan LS, Lawson HW. Cervical cancer screening in the workplace. Research review and evaluation. AAOHN J. 2002;50(1):32-9.

5. [Labour Code of 26 June 1974. J Laws 1974, No. 24, item 141]. Polish.

6. [Occupational Health Services Law of 27 June 1997. J Laws 2014, item 1184]. Polish.

7. World Health Organization [Internet]. Geneva: The Organization; 2021 [cited 2020 Nov 2]. The 1st International Conference on Health Promotion, Ottawa, 1986. Available from: http:/www.who.int/healthpromotion/conferences/previous/ ottawa/en/.
8. Puchalski K, Korzeniowska E. [Workplace health promotion in public health policies in Poland]. Med Pr. 2008;59(1): 55-64. Polish.

9. Luxembourg Declaration on Workplace Health Promotion in the European Union 2007 [cited 2020 Nov 2]. Perugia: European Network for Workplace Health Promotion; 2018. Available from: http://www.enwhp.org/fileadmin/rsdokumente/dateien/ Luxembourg_Declaration.pdf

10. Marcinkiewicz A, Wojda M, Walusiak-Skorupa J, Hanke W, Rydzyński K. [Analysis of tasks of occupational health services accomplished in Poland, 1997-2014. Do we exploit the full potential of prophylactic examinations of workers?] Med Pr. 2017;68(1):105-19, https://doi.org/10.13075/mp.5893.00509. Polish.

11. Caplan LS, Coughlin SS. Worksite breast cancer screening programs: a review. AAOHN J. 1998;46(9):443-51.

12. Douglas NC, Baillie L, Soyer HP. Skin cancer screening of outdoor workers in Queensland. Med J Aust. 2011;195(2):100-1.

13. Nicholls R, Perry L, Gallagher R, Duffield C, Sibbritt D, Xu X. The personal cancer screening behaviours of nurses and midwives. J Adv Nurs. 2017;73(6):1403-20, https://doi.org/10.1111/ jan.13221.

14. Uchwała nr 10 Rady Ministrów z dnia 4 lutego 2020 r. w sprawie przyjęcia programu wieloletniego pn. Narodowa Strategia Onkologiczna na lata 2020-2030. Off Gaz Rep Pol 2020, item 189. Polish.

15. Ministry of Health [Internet]. Warsaw: The Ministry; 2011 [cited 2020 Nov 2]. Report on the Implementation of the National Program for Combating Cancer in 2010. Available from: http://www2.mz.gov.pl/wwwfiles/ma_struktura/ docs/sprawozdanie_npzchn_12122011.pdf.

16. Statistics Poland [Internet]. Warszawa: The Office; 2007 [cited 2020 Nov 10]. Stan Zdrowia Ludności Polski w przekroju terytorialnym w 2004 roku. Available from: https://stat.gov. $\mathrm{pl} /$ obszary-tematyczne/zdrowie/zdrowie/stan-zdrowia-ludnosci-polski-w-przekroju-terytorialnym-w-2004-r,5,1.html. Polish. 
17. Statistics Poland [Internet]. Warszawa: The Office; 2012 [cited 2020 Nov 10]. [Health and healthcare in 2011]. Available from: https://stat.gov.pl/cps/rde/xbcr/gus/zo_zdrowie_i ochrona_zdrowia_w_2011.pdf. Polish.

18. Januszek-Michalecka L, Nowak-Markwitz E, Banach P, Spaczynski M. Effectiveness of the National PopulationBased Cervical Cancer Screening Programme in Poland outcomes, problems and possible solutions 7 years after implementation. Ann Agric Environ Med. 2013;20(4):859-64.

19. Marcinkiewicz A. [Resources and activities of occupational health service units in Poland. An analysis of the mandatory medical reporting for 2014-2018]. Med Pr 2020;71(4):42940, https://doi.org/10.13075/mp.5893.00982.

20. Edwards N, Boulet J. Implementing breast cancer screening guidelines: results of the Ontario Health Status Survey. Am J Prev Med. 1997;13(2):143-9.

21. Sorensen G, Stoddard AM, LaMontagne AD, Emmons K, Hunt MK, Youngstrom R, et al. A comprehensive worksite cancer prevention intervention: behavior change results from a randomized controlled trial (United States). J Pub Health Policy. 2003;24(1):5-25.

22. Wiszniewska M, Magnuska J, Lipińska-Ojrzanowska A, Pepłońska B, Hanke W, Kalinka J, et al. [The prophylactic operation model integrated with occupational health care - prophylactic of some types of cancers among women]. Med Pr. 2018;69(4):439-55, https://doi.org/10.13075/mp.5893.00665.
23. Suggs TF, Cable TA, Rothenberger LA. Results of a worksite educational and screening program for hypertension and cancer. J Occup Med. 1990;32(3):220-5, https://doi.org/ 10.1097/00043764-199003000-00008.

24. Crombie K, Hancock K, Chang E, Vardanega L, Wonghongkul T, Chanakok A, et al. Breast screening education at Australian and Thai worksites: a comparison of program effectiveness. Contemp Nurse. 2005;19(1-2):181-96, https:// doi.org/10.5172/conu.19.1-2.181.

25. Gadgil A, Sauvaget C, Roy N, Muwonge R, Kantharia S, Chakrabarty A, et al. Cancer early detection program based on awareness and clinical breast examination: Interim results from an urban community in Mumbai, India. Breast. 2017;31:85-9, https://doi.org/10.1016/j.breast.2016.10.025.

26. Jassem J, Krzakowski M, Bobek-Billewicz B, Duchnowska R, Jeziorski A, Olszewski W, et al. [Breast cancer]. In: Jassem J, Krzakowski M, editors. [Recommendations for diagnostics and therapy]. Vol. 4. Gdańsk: Via Medica; 2018. p. 210-56. Polish.

27. Rantanen J, Kim R. [Situation analysis and recommendations for stewardship on workplace health promotion in Poland] [Internet]. Copenhagen: The WHO Regional Office for Europe; 2012 [cited 2020 Nov 10]. Available from: http://www.euro.who.int/_data/assets/pdf_file/0011/181856/ e96758-Eng.pdf?ua=1.

This work is available in Open Access model and licensed under a Creative Commons Attribution-NonCommercial 3.0 Poland License - http://creativecommons.org/ licenses/by-nc/3.0/pl/deed.en. 